08

\title{
Свойства наночастиц серебра в присутствии диспрозия
}

\author{
() С.И. Расмагин, ${ }^{1}$ В.И. Крыштоб, ${ }^{1}$ И.К. Новиков ${ }^{2}$ \\ ${ }^{1}$ Институт общей фоизики им. А.М. Прохорова РАН, \\ 119991 Москва, Россия \\ ${ }^{2}$ Национальный исследовательский ядерный университет МИФИ, \\ 115409 Москва, Россия \\ e-mail: rasmas123@yandex.ru
}

(Поступило в Редакцию 25 декабря 2017 г.)

Связывание разными способами ионов редкоземельных металлов с наночастицами позволяет создавать материалы с новыми свойствами. Методом „зеленого“ синтеза были получены наночастицы серебра, функционализированные ионами $\mathrm{Dy}^{3+}$. Измерены спектры поглощения и фотолюминесценции коллоидных растворов, проанализированы характеристики полученных наночастиц $\mathrm{Ag}$ на электронном микроскопе. Результаты наблюдений хорошо согласуются с оценками, полученными по спектрам поглощения с помощью классической модели. Определена форма (в основном сферическая), размеры наночастиц $(d=70 \mathrm{~nm})$, объемная доля серебра в коллоидном растворе $f=6 \cdot 10^{-4}$. Функционализирование наночастиц серебра ионами диспрозия в рамках использованной в настоящей работе методики можно распространить на другие редкоземельные элементы.

DOI: 10.21883/JTF.2018.12.46790.2614

\section{Введение}

Известно, что в наночастицах серебра наблюдается плазмонный резонанс, который приводит к значительному росту локальной напряженности поля и сопровождается новыми оптическими эффектами, такими как усиление люминесценции и поглощения света [1], усиление комбинационного рассеяния [2], апконверсия [3,4] и др. аналогичные явления, относящиеся к ,плазмонике“ [5]. С другой стороны, исследование важного вопроса о влиянии плазмонных эффектов на оптические характеристики редкоземельных металлов в настоящее время еще только начинается, например, в работе [6] отражены результаты по плазмонному усилению ап-конверсии в наночастицах $\mathrm{NaYF}_{4}$, допированных ионами $\mathrm{Yb}^{3+}$, $\mathrm{Er}^{3+}$. При определенных условиях плазмонный резонанс может уменьшать порог накачки при получении апконверсии на частицах редкоземельных элементов [6,7].

Известно множество различных химических и физических методов синтеза наночастиц серебра $[8,9]$, среди которых особое место занимают методы „зеленого“ синтеза, когда в качестве восстанавливающих соли металлов и стабилизирующих образующиеся наночастицы реагентов используются различные продукты метаболизма растений [10-12]. Такой подход отличается от обычных физических и химических методов синтеза наночастиц простотой, дешевизной, легкой масштабируемостью и „экологичностью“, т. е. безопасностью для окружающей среды и совместимостью с живыми тканями, что позволяет в принципе использовать полученные наночастицы для медицинских целей [13].

Недостатком метода „зеленого“ синтеза является трудность интерпретации протекающих при этом процессов, связанная с большим разнообразием участвующих биохимических реагентов, а также проблемы, связанные с очисткой получаемых наночастиц Ag. Первоначально в качестве „зеленого“ реагента авторами использовались водные экстракты, полученные из сушеных листьев мяты перечной, которые затем были заменены раствором ментола, являющегося основным компонентом экстракта мяты. Оказалось, что замена экстракта мяты ментолом позволяет получать аналогичные наночастицы Ag, отличающиеся лишь формой и деталями структуры. С использованием ментола были синтезированы коллоидные растворы наночастиц серебра и наночастиц серебра, функционализированные ионами диспрозия.

Целью настоящей работы являлось исследование влияния наночастиц серебра на оптические свойства ионов диспрозия в коллоидном растворе.

\section{Экспериментальная часть}

Для приготовления водных растворов растительных экстрактов $6 \mathrm{~g}$ сушеных листьев мяты перечной заливали $100 \mathrm{ml}$ деионизованной воды, нагретой до $600^{\circ} \mathrm{C}$. Растворы листьев мяты нагревали 15 min на кипящей водяной бане, а затем охлаждали до комнатной температуры в течение 45 min и фильтровали через бумажные фильтры. Полученный экстракт мяты имел желтовато-зеленый цвет. Для биосинтеза наночастиц серебра к $50 \mathrm{ml} 0.006 \mathrm{M}$ раствора $\mathrm{AgNO}_{3}$ добавляли $2.5 \mathrm{ml}$ приготовленного фитоэкстракта мяты. Полученные растворы оставили на сутки при комнатной температуре. Дальнейшие наблюдения и экспериментальные исследования проводились при температуре $t=25^{\circ} \mathrm{C}$. В результате был получен коллоидный раствор, содержащий наночастицы серебра, что подтверждалось результатами просвечивающей электронной микроскопии, а также анализом спектра 
поглощения, который содержал пик вблизи длины волны $450 \mathrm{~nm}$ для наночастиц серебра.

Аналогичные результаты были получены при замене экстракта мяты на раствор ментола, полученный растворением $1 \mathrm{~g}$ кристаллического ментола в $100 \mathrm{ml}$ воды, нагретой на водяной бане до $60^{\circ} \mathrm{C}$. Коллоиды, содержащие наночастицы серебра, образовывались при комнатной температуре при добавлении $0.2 \mathrm{ml}$ указанного раствора ментола к $10 \mathrm{ml} 0.006 \mathrm{M}$ раствора $\mathrm{AgNO}_{3}$. Для получения функционализированных диспрозием наночастиц $\mathrm{Ag}$ указанные коллоидные растворы объемом $10 \mathrm{ml}$ выдерживались в течение $24 \mathrm{~h}$ при комнатной температуре, после чего к ним добавляли $0.5 \mathrm{ml} 0.007 \mathrm{M}$ водного раствора $\mathrm{DyCl}_{3}$. Образующийся при этом и выпавший в осадок хлорид серебра отделялся от коллоида на центрифуге со скоростью вращения $6000 \mathrm{rpm}$ в течение 15 min. В результате получался прозрачный коллоидный раствор, содержащий наночастицы серебра функционализированнные диспрозием.

\section{Результаты и их обсуждение}

Внешний осмотр растворов показал, что введение раствора соли в водный раствор фитоэкстракта приводит к резкому изменению окраски раствора от светлых оттенков до темно-коричневого. Окраска растворов изменяется в зависимости от концентрации образующихся частиц серебра. Изменение окраски раствора мяты перечной от светло-зеленого до темно-коричневого связано с появлением характерной для коллоидных наночастиц серебра плазмонной полосы поглощения с длиной волны около $400 \mathrm{~nm}$. Обнаружено, что по истечении $24 \mathrm{~h}$ наночастицы серебра коагулируют с выпадением в осадок. При добавлении ментола в раствор соли наблюдалось слабое желтое окрашивание раствора, он приобретал слабую опалесценцию из-за образования коллоидных наночастиц серебра.

После выделения из раствора наночастицы серебра исследовались на просвечивающем электронном микроскопе с целью оценки их формы и размеров (рис. 1). При этом большинство наночастиц серебра имели форму, близкую к сферической или квазисферической, а их размеры находились в пределах 60-80 nm.

Для приготовленных коллоидных растворов были также измерены спектры поглощения в зависимости от длины волны излучения с помощью спектрометра SpectraSuite USB2000 ${ }^{+}$и вольфрамовой лампы LS-1 в качестве источника возбуждающего света (рис. 2). Погрешность измерений спектрометра составляла $\sim 5 \%$. Диапазон спектра поглощения изменялся в пределах 300-700 nm. Из графика на рис. 2 видно, что спектр поглощения имеет характерную полосу поглощения с максимумом, соответствующим длине волны $450 \mathrm{~nm}$. На основе данных спектра поглощения были сделаны оценки размеров наночастиц серебра и дана оценка объемной доли серебра в коллоидном растворе. При расчете

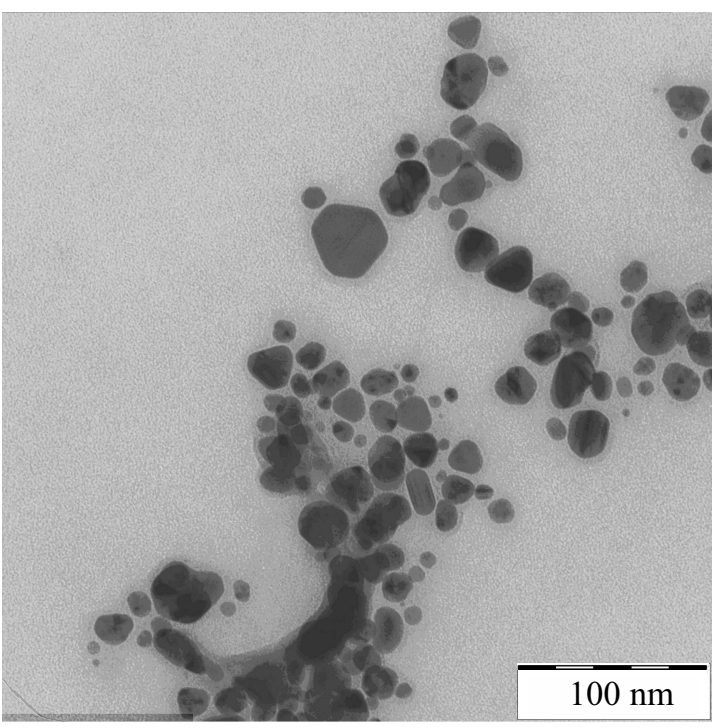

Рис. 1. ТЕМ изображение наночастиц $\mathrm{Ag}$

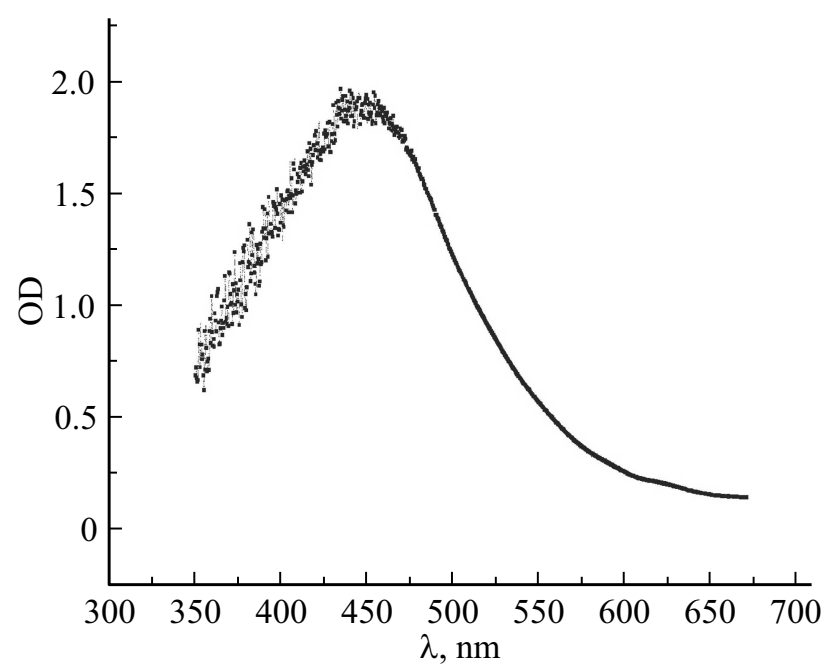

Рис. 2. Спектр поглощения наночастиц серебра в коллоидном растворе. OD - оптическая плотность, $\lambda, \mathrm{nm}$ - длина волны света.

параметров наночастиц $\mathrm{Ag}$ использовалась классическая теоретическая модель [14]. В этой модели спектр диэлектрической проницаемости коллоида может быть описан c помощью спектра диэлектрической проницаемости объемного металла и окружающей среды, а влияние размера частиц учитывается как увеличение частоты столкновений электронов в металле. В целом плазменная частота металла и показатель преломления окружающей среды задают положение максимума поглощения коллоидного раствора, высота которого определяется объемной долей металла, а ширина - частотой столкновений электронов с учетом вклада, связанного с размерами наночастиц металла. Применение данной модели к спектру поглощения дает следующие оценки: средний 
размер наночастиц серебра порядка $-70 \mathrm{~nm}$, объемная доля серебра в коллоидном растворе $f=6 \cdot 10^{-4}$. Сравнивая размер наночастиц серебра, полученных из спектра поглощения $d=70 \mathrm{~nm}$, и размер наночастиц серебра, полученных методом электронной микроскопии $(d=60-80 \mathrm{~nm})$, можно видеть, что размеры наночастиц серебра совпадают по порядку величины.

Можно предположить, что физико-химический процесс создания наночастиц серебра при использовании ментола состоит из следующих стадий:

1) восстановление атомов серебра (химическая реакция)

$$
\begin{aligned}
\mathrm{Ag}^{+} \mathrm{NO}_{3}^{-}+ & \left(\mathrm{C}_{10} \mathrm{H}_{19}\right)^{+}(\mathrm{OH})^{-}=\mathrm{Ag}^{0}+\left(\mathrm{C}_{10} \mathrm{H}_{19}\right)^{+}=\mathrm{O}^{-} \\
& +\mathrm{H}^{+} \mathrm{NO}_{3}^{-},
\end{aligned}
$$

2) образование зародышей (ван-дер-ваальсовское взаимодействие)

$$
\begin{aligned}
\mathrm{Ag}^{0} & +\left(\mathrm{C}_{10} \mathrm{H}_{19}\right)^{+}=\mathrm{O}^{-}+\mathrm{H}^{+} \mathrm{NO}_{3}^{-} \\
& =\left(\mathrm{Ag}^{0}\left(\mathrm{C}_{10} \mathrm{H}_{19}\right)^{+}=\mathrm{O}^{-}\right)+\mathrm{H}^{+} \mathrm{NO}_{3}^{-},
\end{aligned}
$$

3) рост и образование наночастиц серебра (мицелл)

$$
\begin{aligned}
& \left(\mathrm{Ag}^{0}\left(\mathrm{C}_{10} \mathrm{H}_{19}\right)^{+}=\mathrm{O}\right)+\mathrm{H}^{+} \mathrm{NO}_{3}^{-} \\
& \quad=\left\{\left(\mathrm{Ag}^{0}\left(\mathrm{C}_{10} \mathrm{H}_{19}\right)^{+}=\mathrm{O}^{-}\right) \mathrm{H}^{+}\right\}+\left(\mathrm{NO}_{3}^{-}\right),
\end{aligned}
$$

состоящих из металлического ядра $\mathrm{Ag}^{0}$, оболочки $\left(\mathrm{C}_{10} \mathrm{H}_{19}\right)^{+}=\mathrm{O}^{-}$и противоионов $\mathrm{H}^{+}$. Отметим, что для „зеленого“ синтеза наночастиц серебра в растворе мяты помимо ментола присутствуют другие вещества (пулегон, цинеол, флавон), способные участвовать в создании и образовании наночастиц Ag.

$\mathrm{C}$ учетом того что добавленный к коллоиду $\mathrm{DyCl}_{3}$ не участвовал в реакции восстановления коллоидных частиц серебра, диспрозий мог участвовать лишь в качестве противоиона при формировании внешней оболочки частиц Ag.

На рис. 3 приведены спектры фотолюминесценции исходного коллоида и коллоида с наночастицами $\mathrm{Ag}$. Из рис. 3 видно, что созданные наночастицы серебра приводят к уменьшению максимума фотолюминесценции коллоидного раствора с ионами диспрозия в 5 раз для перехода ${ }^{4} F_{9 / 2} \Rightarrow{ }^{6} H_{13 / 2}$. Уменьшение максимума спектра фотолюминесценции предположительно происходит за счет безызлучательных переходов и передачи энергии плазмонной наночастице Ag. Поэтому этот факт можно объяснить отрицательным влиянием образованных наночастиц $\mathrm{Ag}$ с их внешней оболочкой на фотолюминесценцию раствора с ионами диспрозия. Как сказано выше, ионы диспрозия являются противоионами внешней оболочки наночастиц $\mathrm{Ag}$ и поэтому находятся в непосредственной близости с наночастицами. При этом наночастицы $\mathrm{Ag}$ сильно уменьшают (даже гасят) фотолюминесценцию ионов диспрозия, непосредственно

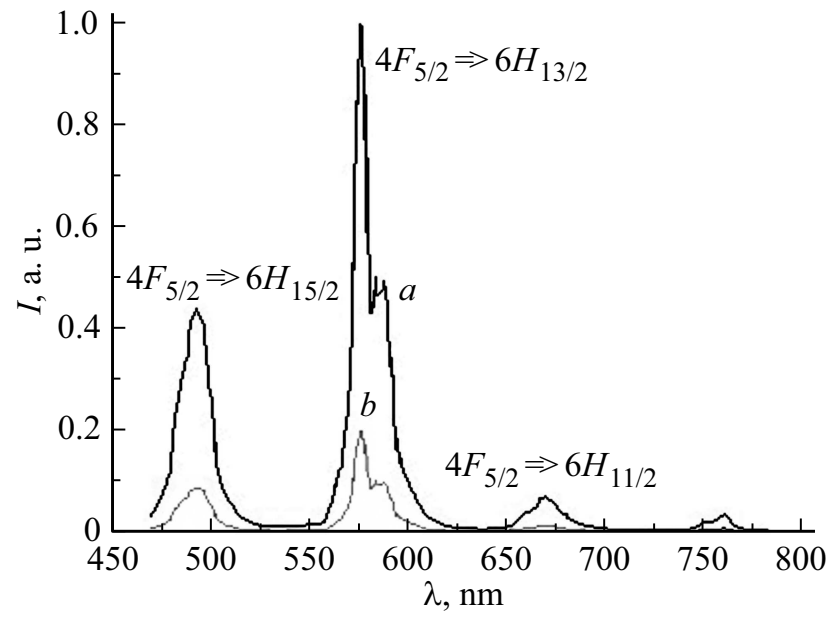

Рис. 3. Спектры фотолюминесценции при возбуждении на длине волны $450 \mathrm{~nm} . a-$ без наночастиц, $b-$ с наночастицами.

связанных с наночастицами Ag. Например, для кристаллических частиц легированных редкоземельными элементами, переход от микро- к наноразмерам приводит к усилению роли дефектов, а именно к концентрационному гашению люминесценции редкоземельных ионов [15]. При этом можно допустить, что в коллоидном растворе часть ионов диспрозия остается в свободном (т.е. не связанном с наночастицами $\mathrm{Ag}$ ) состоянии. Эти „свободные“ ионы Dy ${ }^{3+}$ способны люминесцировать при световом возбуждении. Это допущение разумно, так как наличие наночастиц $\mathrm{Ag}$ не уширяет спектр фотолюминесценции коллоидного раствора $\mathrm{Dy}^{3+}$. Если справедливо предложенное нами объяснение уменьшения максимума фотолюминесценции растворов ионов $\mathrm{Dy}^{3+}$ в присутствии наночастиц $\mathrm{Ag}$ приблизительно в 5 раз, то можно утверждать, что количество ионов $\mathrm{Dy}^{3+}$ связанных с наночастицами $\mathrm{Ag}$ соотносится к количеству свободных ионов $\mathrm{Dy}^{3+}$ как $5: 1$.

Можно рассмотреть другой вариант, когда максимум фотолюминесценции уменьшается по причине безыизлучательных переходов и передачи энергии от всех образованных ионов диспрозия плазмонной наночастице $\mathrm{Ag}$. Присутствие ионов $\mathrm{Dy}^{3+}$ вблизи поверхности металлической наночастицы влияет на интенсивность фотолюминесценции и уменьшение времени релаксации, что определяется передачей энергии с возбужденного иона диспрозия к плазмонной наночастице при условии, что возбужденное состояние иона находится в резонансе с плазмонной зоной наночастицы серебра, как и наблюдается в нашем случае. Подобный механизм был детально исследован в твердотельной системе - стекле, в состав которого были введены ионы диспрозия [16]. В этой работе было определено время релаксации люминесценции перехода ${ }^{4} F_{9 / 2} \Rightarrow{ }^{6} H_{13 / 2}$. Было показано, что кривая релаксации интенсивности фотолюминесценции 


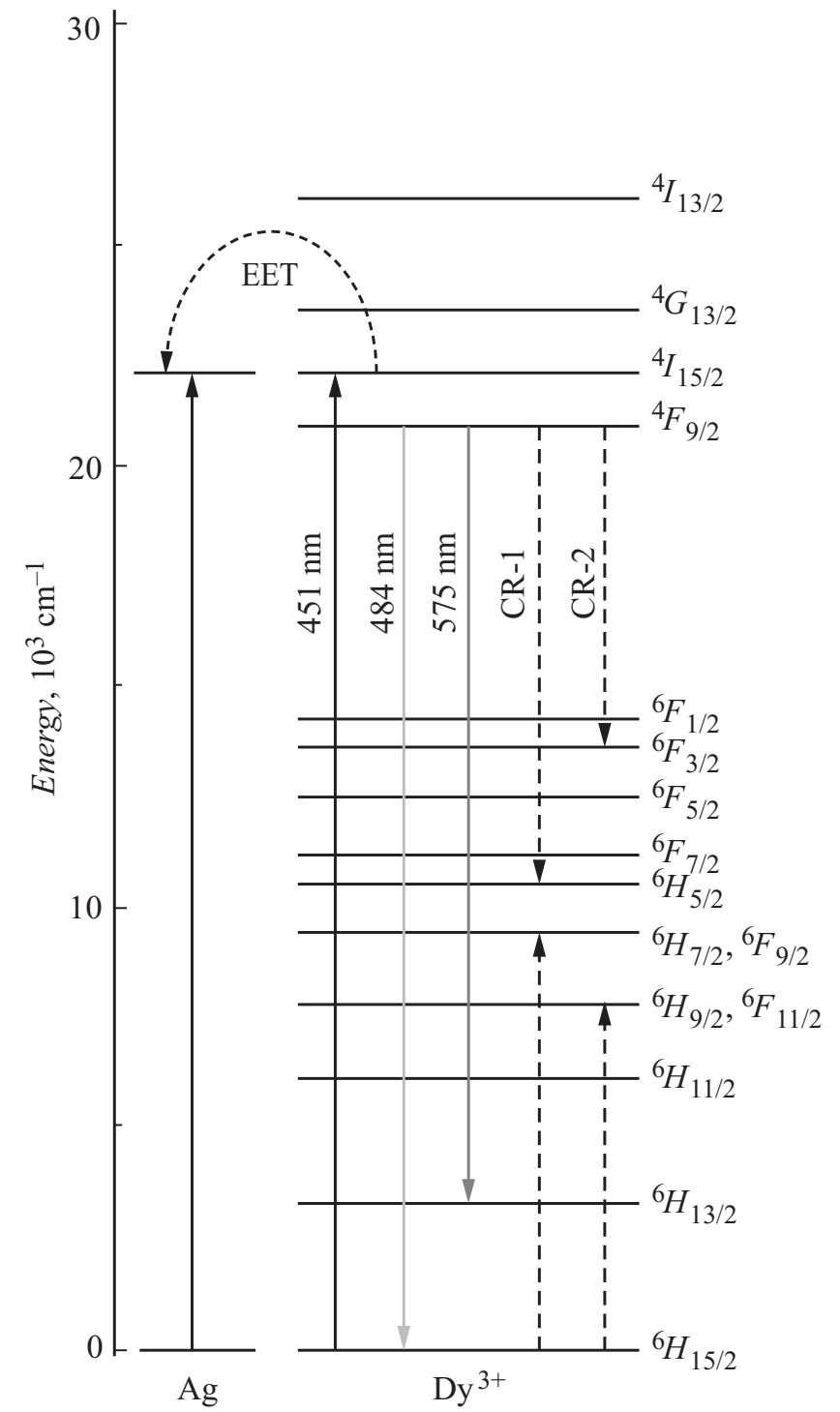

Pис. 4. Энергетическая диаграмма иона $\mathrm{Dy}^{3+}$ и плазмонная зона наночастицы Ag, приводящая к тушению люминесценции. Показаны пути внутрисистемного переноса энергии CR-1 и CR-2.

хорошо описывается двойной экспонентой вида

$$
I(t)=B_{s} \exp \left(-\frac{t}{\tau_{s}}\right)+B_{l} \exp \left(-\frac{t}{\tau_{l}}\right),
$$

где $B_{s}$ и $B_{l}$ - константы, индексы $s$ и $l$ соответствуют короткому и длинному времени релаксации возбужденного состояния ${ }^{4} F_{9 / 2}$. Наиболее короткое время было связано с релаксацией ионов $\mathrm{Dy}^{3+}$ через состояния CR-1 и CR-2 (рис. 4), а наиболее длинное приписывают релаксации без переноса энергии.

Таким образом, образование наночастиц $\mathrm{Ag}$ в коллоидном растворе уменьшает интенсивность фотолюминесценции коллоидного раствора с диспрозием приблизительно в 5 раз. Поэтому для выяснения условий, при которых не происходит уменьшения фотолюминес- ценции, необходимо провести дальнейшие исследования коллоидных растворов ионов $\mathrm{Dy}^{3+}$ с наночастицами $\mathrm{Ag}$ и провести анализ их данных. Заметим, что сделать это не так просто, как в случае твердотельных матриц. Предварительно можно провести исследования в полимерной матрице в вязкотекущем состоянии.

\section{Заключение}

Таким образом, в настоящей работе методом зеленого синтеза был получены наночастицы серебра, модифицированные ионами диспрозия. Измерены и изучены спектры поглощения и фотолюминесценции полученных коллоидных растворов диспрозия с наночастицами серебра и без них, а также представлены данные электронной микроскопии синтезированных наночастиц серебра. Определены форма (в основном сферическая и квазисферическая), размеры наночастиц серебра $(d=70 \mathrm{~nm})$ и объемная доля серебра в коллоидном растворе $f=6 \cdot 10^{-4}$. Даны возможные объяснения уменьшения фотолюминесценции коллоидных растворов ионов диспрозия с наночастицами серебра. Предполагаем, что данный подход можно распространить на другие редкоземельные элементы,

\section{Список литературы}

[1] Geddes Ch.D. Metal-enhanced fluorescence nanoparticles. Pat. US 20090022766 A1.

[2] Contreras-Caceres R., Sierra-Martin B., Fernandes-Barbero A. Ch. 7 in Microsensors. Ed I. Minin, 2011. Available at: http://www.e-booksdirectory.com/details.php?ebook $=6386$

[3] Chen G., Damasco J., Qiu H., Shao W., Ohulchanskyy T., Valiev R., Wu X., Han G., Wang Y., Yang C., Ågren H., Prasad P. // Nano Lett. 2015. Vol. 15. P. 7400. DOI: 10.1021/acs.nanolett.5b02830

[4] Zhang F. Photon upconversion materials. Berlin, Heidelberg: Springer, Springer-Verlag, 2015.

[5] Di Bartolo B., Collins J., Silvestri L. eds. Nano-Structures for Optics and Photonics. Springer, 2015.

[6] Park W., Lu D., Ahn S. // Chem. Soc. Rev. 2015. Vol. 44. P. 2940.

[7] Xu W., Min X., Chen X., Zhu Y., Zhou P., Cui S., Xu S., Tao L., Song H. // Scientific Rep. 2014. Vol. 4. P. 1.

[8] Krutyakov Yu.A., Kudrinskiy A.A., Olenin A.Yu., Lisichkin G.V. // Russian Chem. Rev. 2008. Vol. 77. P. 233. http://www.turpion.org/php/paper.phtml?journal_id=rc\&paper $\_$id $=3751$

[9] Evanoff D.D., Chumanov G. // Chem. Phys. Lett. 2005. Vol. 6. P. 1221.

[10] Ahmed S., Ahmad M., Swami B.L., Ikram S. // J. Adv. Res. 2016. Vol. 7. P. 17.

[11] Mittal A.K., Chisti Y., Banerjee U.C. // Biotechnology Adv. 2013. Vol. 31. P. 346.

[12] Basiuk V.A., Basiuk E.V. Green Processes for Nanotechnology. Springer, 2015. P. 446.

[13] Kumar-Parashar U.K., Saxena P.S., Srivastava A. // J. Nanomater. Biostructures. 2009. Vol. 4. P. 159. Available at: http://www.chalcogen.ro/1Kumar-Parashar.pdf 
[14] Hovel J.H., Fritz S., Hilger A., Kreibig U., Vollmer M. // Phys. Rev. B. 1993. Vol. 48. N 24. P. 18178-18188. DOI: 10.1103/PhysRevB.48.18178

[15] Barrera E.W., Pujol M.C., Cascales C., Zaldo C., Park K.H., Choi S.B., Rotermund F., Carvajal J.J., Mateos X., Aguiló M., Díaz F. // Appl. Phys. B. 2012. Vol. 106. N 2. P. 409-417. DOI: $10.1007 / \mathrm{s} 00340-011-4691-0$

[16] Amjad R.J., Dousti M.R., Iqbal A., Hussain S.Z., Sahar M.R., Shaukat S.F. // Measurement. 2015. Vol. 74. P. 87-91.

http://dx.doi.org/10.1016/j.measurement.2015.07.002 